\title{
Scientists' Access and Retrieval of References Cited in Their Recent Journal Articles
}

Julie Hallmark

\begin{abstract}
Scientific authors of 319 articles in nineteen current research journals were asked to explain how they: (1) first became aware of a specific reference which they cited, and (2) how they subsequently obtained it. Disciplines represented in the study were chemistry, physics, mathematics, biology, and geology. Of several possible modes of access, personal contacts and references in the literature were most important. Actual retrieval occurred primarily through library subscriptions and copies from colleagues. Variations among disciplines appeared in the use of databases, current awareness services, and personal journals. Scientists' perceptions of problems with their journal literature and suggestions for improvement revealed some interesting ideas and a few misconceptions. Findings have implications for present and future roles played by the academic library in serving its scientific clientele.
\end{abstract}

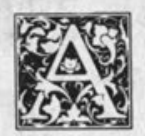

cademic library administrators, science librarians, and scientists are deeply concerned about increases in scientific journal subscription costs and subsequent cuts in library holdings which are occurring across the United States. Affected by publisher-imposed price increases and unfavorable exchange rates, scientific serial prices continue to escalate. In September 1992 Faxon announced price increases for 1993 of 9.5 percent for titles published in the United States, 28.5 percent for nonUnited States published titles from publishers with fixed exchange rates, and 20.0 percent for non-United States published titles from publishers with nonfixed exchange rates. ${ }^{1}$ In his analysis of serial price trends, Adrian Alexander provides subject categories with the highest average journal prices; chemis- try heads the list at $\$ 828.08$ followed by physics, physiology, science, microbiology, finance, mathematics, and astronomy. ${ }^{2}$ As an excellent recent study from the Association of Research Libraries (ARL) observed, "Many speak of a 'serials crisis' at the heart of library difficulties today, and it is prices, and in particular science journal prices, that drive the crisis." ${ }^{3}$

Academic scientists have addressed the problem from several angles. Some have investigated the relative value of journals in their discipline. For example, research by $\mathrm{H}$. $\mathrm{H}$. Barschall and by Barschall and J. R. Arrington analyzed the cost-effectiveness of physics journals based on a ratio of cost per 1,000 characters and the impact factor. ${ }^{4.5}$ The latter, developed by the Institute for Scientific Information, takes into account citation rates for the title, among other variables. Barschall 
found variations in the ratio of cost to impact of from 0.063 to 54 , a factor of 850 .

Some science departments have raised money for their journal collections through endowments or donations, while department chairs fight doggedly to maintain or to increase their share of the journal budget pie. We can certainly understand and sympathize with their concern; at stake is the primary journal, for more than $\mathbf{3 0 0}$ years the single most critical method of scientific communication and the official record of science.

Controversies abound. Librarians and users alike debate the merits of electronic access versus paper subscriptions, and many question the value to users of the academic library model which emphasizes access over holdings. Defensive administrators attempt to justify the latest round of cancellations. Publishers resent being used as examples of unreasonable price increases, and some think that the increasingly comprehensive approaches to resource sharing violate copyright. In this hostile atmosphere, research which addresses the methods used by scientists to seek and retrieve journal articles should contribute useful data for academic librarians to aid in decision making.

Access and retrieval of journal articles by scientists have been investigated over the years by a number of researchers, frequently within broader studies of information-seeking behavior. Valuable bibliographies appear in the volumes by Nancy Pruett and in Information Technology and the Conduct of Research: The User's View. ${ }^{6,7}$ Constance C. Gould and Karla Pearce prepared an excellent summary covering all scientific disciplines for the Research Libraries Group, Inc. ${ }^{8}$

This article focuses on two basic questions: (1) How do scientists first become aware that a particular journal article exists? and (2) How do scientists actually obtain a copy of the desired article? Hypotheses of the investigation are as follows:

- The library's chief contribution is that of journal repository plus a mechanism for document delivery for those items not owned.

- Academic librarians play a negligible role in directing the scientists' attention to specific publications of interest.

- Scientists' dependence on bibliographic databases is minimal with the exception of chemists, who locate more through databases than do workers in other disciplines.

- The majority of references come to the attention of scientists through personal contacts and references in the published journal literature.

- Physical retrieval of the majority of references is through the library's journal collection.

\section{METHODOLOGY}

A pioneering study of scientific communication in the United States by D. W. King and others demonstrated the effectiveness of asking scientists directly how they first became aware of a particular article they cited and how they actually obtained a copy. ${ }^{9}$ King's methodology, slightly modified, was used in the present study to contact 319 U.S. scientists in biology, physics, chemistry, mathematics, and geology. In addition to specifying their mode of access and retrieval, participants had an opportunity to comment on problems encountered and to suggest improvements in this process.

Nineteen journals were selected on the basis of recommendations from scientists in the respective disciplines and through independent evaluations. ${ }^{10} \mathrm{Ta}-$ ble 1 lists the journal titles used in the study; articles taken from each were chosen by random sampling. Examination of the information-seeking behavior of authors of articles in these highly prestigious research journals provides input from some of America's most talented scientists. The sample of 319 articles in these journals, published during the last six months of 1991, formed the corpus of literature for the research. The five disciplines were equally represented, approximately, in terms of the number of articles from each.

Most of the authors contacted were in academic institutions: chemistry (100 percent); biology (91 percent); mathematics ( 91 percent); physics ( 85 percent); and geology (70 percent). Private corpora- 
TABLE 1

JOURNALS USED IN THE STUDY

\begin{tabular}{l} 
Biology \\
American Journal of Botany \\
Anatomical Record \\
Journal of Bacteriology \\
Proceedings of the National Academy of \\
Science \\
Chemistry \\
Journal of the American Chemical Society \\
Journal of Inorganic Chemistry \\
Journal of Organic Chemistry \\
Geology \\
American Journal of Science \\
Bulletin of the Geological Society of America \\
Geology \\
Mathematics \\
American Journal of Mathematics \\
Annals of Mathematics \\
Society for Industrial and Applied Mathe- \\
matics (SIAM) Review \\
SIAM Journal of Applied Math \\
SIAM Journal on Science and Statistical \\
Computing \\
Physics \\
Physical Review A \\
Physical Review B \\
Physical Review C \\
Physical Review D \\
\hline
\end{tabular}

tions, government agencies, and research institutes accounted for the remainder, especially in geology, with relatively high employment in federal and state surveys. These data are not surprising, given the research nature of the journals and the pressure to publish in academia. Thus, the results of the study strongly represent the academic community.

A single cited journal reference from each article was selected with the goal of achieving the following overall sample for each discipline:

- Citations published 1980-1991

- Citations published 1979 or earlier

- Citations in a foreign language

5 percent
Obviously, the proportion of each of these categories varies by discipline; these percentages represent an approximate (somewhat arbitrary) average for purposes of consistency among the various subject areas. Thus, variation in access and retrieval in terms of the age of the citation or its language might be observable.

For each article in the sample, the first author received a personal letter. (See Appendix A.) The letter supplied complete bibliographic information on the scientist's 1991 article along with the selected journal citation in exactly the format it had been cited. The request to complete a "brief form" solicited information on: (1) how the citation had first come to the scientist's attention and (2) how the citation had actually been obtained. Thus, the form reflected the two research questions posed initially and offered these possible modes of access and retrieval:

- Access: Personal Contact; Current Awareness Service; Seminar or Conference; Database (Online or CD-ROM); TraditionalAbstracting/Indexing (A\&I) Service; Reference in the Literature; Suggestion from a Librarian; Browsing in Journals; Don't Remember; Other.

- Retrieval: Library Subscription; Interlibrary Loan; Electronic Copy; Reprint, Preprint, Photocopy from Colleague; Personal Journal; Librarian Gave It to Me; Don't Remember; Other.

In addition, participants were invited to comment on problems encountered in journal access and retrieval and to suggest improvements. A stamped, self-addressed envelope for return mailing completed the packet.

\section{RESULTS}

The return rates for the various disciplines were as follows:
- Chemistry

- Geoscience

- Mathematics

- Biology

- Physics

Some 116 of the scientists returning the form offered comments, some at great length, describing problems
67 percent

80 percent

76 percent

79 percent

75 percent 
TABLE 2

HOW SCIENTISTS FIRST BECOME AWARE OF JOURNAL ARTICLES

\begin{tabular}{lccccc}
\hline & $\begin{array}{c}\text { Physics } \\
\%\end{array}$ & $\begin{array}{c}\text { Chemistry } \\
\%\end{array}$ & $\begin{array}{c}\text { Biology } \\
\%\end{array}$ & $\begin{array}{c}\text { Mathematics } \\
\%\end{array}$ & $\begin{array}{c}\text { Geology } \\
\%\end{array}$ \\
\hline Personal contact & 39 & 29 & 38 & 46 & 37 \\
Reference in the literature & 41 & 36 & 31 & 24 & 28 \\
Browsing in journals & 2 & 7 & 11 & 5 & 26 \\
Seminar or conference & 7 & 0 & 5 & 16 & 5 \\
Database (Online or CD-ROM) & 2 & 9 & 6 & 0 & 0 \\
Traditional A \& I service & 2 & 7 & 0 & 5 & 0 \\
Current awareness service & 0 & 5 & 6 & 0 & 2 \\
Suggestion from a librarian & 2 & 2 & 0 & 0 & 0 \\
Don't remember & 2 & 2 & 2 & 3 & 2 \\
Other & 0 & 2 & 2 & 0 & 0 \\
\hline
\end{tabular}

and suggesting solutions related to journals. The opportunity for these open-ended remarks allowed participants freedom to discuss whatever was on their minds in a creative, unstructured format. A number of common threads run through all the disciplines.

\section{Access}

The results shown in table 2 address the first research question: "How do scientists first become aware that a particular journal article exists?" No appreciable differences could be detected in either access or retrieval for citations in foreign languages, older citations, or newer citations; thus these categories were not separately tabulated. The table shows that, for alerting scientists to journal articles of interest, nothing is more critical than: (1) personal contacts and keeping up with the work of specific researchers; and (2) references in the published literature.

Personal Contacts. Scientists in all disciplines except chemistry and physics depended most heavily on some form of personal contact to learn about journal articles that they subsequently cited. King also found very strong dependence on personal contacts; combining his categories of "preprint or reprint" and "colleague reference," which would be comparable to the present research, resulted in physical sciences (32 percent), life sciences (26 percent), mathematics (43 percent), and environmental sciences (54 percent). ${ }^{11}$

Personal contacts took the form of keeping up with the work of specific researchers over the years; maintaining contact with faculty and graduate students from university days; receiving preprints or reprints from colleagues around the world; and suggestions from their own graduate students, reviewers, or collaborators. Several described complex personal networks of coauthors, students, friends, advisers, and professors.

Numerous comments reinforced the data: "The most valuable is knowing personally the major contributors to the field and staying current with their work." "The 'good guys' publish in the same set of good journals, so usually there's no problem." "Knowing a person and following his or her work is the most important means I have for most of my citations."

References in the Published Literature. Discovering references through the literature was the most significant mode of access in physics and chemistry and the second most significant for all other disciplines. A few scientists described in some detail their use of citation tracking, either forward or backward, to access the reference in question. Science Citation Index consistently received high marks.

Databases and Other A\&I Services. The use of databases (online or CDROM) or traditional A\&I services for ac- 
cess was relatively unimportant except in chemistry. The total of 16 percent ( 9 percent and 7 percent) of the references in chemistry which were accessed through online databases or other A\&I services suggests that these approaches are especially critical to that discipline and reflect chemists' strong orientation toward the literature. Other contributing factors are the high quality of Chemical Abstracts and the generous academic discount for online services offered by the publisher. King obtained similar results, finding relatively high use of A\&I services among physical scientists, who located 20 percent of their references in this manner, and low use among life scientists (4 percent) and mathematicians ( 0 percent). ${ }^{12}$ Julie Bichteler and Dederick Ward as well as A. Gralewska-Vickery found extremely low use of A\&I services and databases among geoscientists. ${ }^{13,14}$

In a nutshell, scientists thought that electronic databases should be more complete, less expensive, and more user-friendly.

In contrast to the low actual use of databases and A\&I services to locate references of interest, 40 percent of the participants who chose to comment discussed online access. They described problems, suggested improvements, and expressed hope for the future of electronic resources, which they perceive as the only effective means of dealing with the mass of scientific literature. Thus, we see the interesting situation of significant dissatisfaction with current databases but high expectations for the future.

Chemists and biologists commented most frequently on databases; geoscientists least. Many described specific problems they had personally encountered, such as delays in updating databases, incomplete files wherein one can't retrieve articles known to exist, lack of retrospective coverage, high costs, inaccurate and/or incomplete addresses of authors of articles, poor coverage in interdisciplinary areas, limitations on rep- resentation of graphics and illustrations, slow response times, inefficiency of menu-driven software, complex protocols which require constant practice to stay competent, personal dislike of online searching, the librarian's being unavailable to conduct a search because of other responsibilities, and time-of-day constraints on searching in order to save money.

One-quarter of those who mentioned some aspect of electronic applications complained of difficulties with keyword searching. Use of keywords is "limiting," "a real pain," unproductive as "only a small portion of relevant articles" are retrieved, difficult because articles are "not indexed under the keywords I would have expected," "not standardized," etc. Two scientists could not retrieve their own articles by keyword! Participants in the study tended to blame the system, and one suggested that all indexing should be done by scientists.

Interestingly, no one mentioned thesauri or controlled vocabulary, suggesting that these end users need more instruction and assistance in order to be effective searchers. Dr. Damon Ridley of the University of Sydney, an internationally known expert on searching CAS ONLINE, has pointed out that chemists do not use the "Index Guide" and that most scientists simply don't understand the use of a thesaurus. ${ }^{15}$ As STN representative in Australia, he is concerned both with inefficiency of online searching by scientists and by poor title construction by authors who do not adequately consider future keyword retrieval.

In a nutshell, scientists thought that electronic databases should be more complete, less expensive, and more userfriendly. Standardized protocols and more sophisticated software such as expert systems geared to individual interests and needs were seen as possible aids in access. Several scientists mentioned the desirability of free Internet access to A\&I and current awareness services.

Browsing in Journals. Most scientists argue that browsing in library and personal journal issues is of critical impor- 
tance in keeping up with the literature. Geologists and biologists found the largest number of articles in this manner. Those in other disciplines appeared to find browsing less productive. King found considerably higher dependence in all disciplines on identification of useful references through "subscription copies" than did the present study. ${ }^{16}$

Database access does not necessarily compensate for the lack of physical access, as a chemist eloquently describes:

One of the most disturbing aspects of the continuing evolution to computer databases as the principal means for finding information is an information tunneling effect. The database method of search forces you to focus, to have a fairly well-defined idea of what you are searching for. Sometimes that is fine.

But often, my best ideas come when I am browsing through journals, randomly reading bits of information here and there as different diagrams and structures catch my eye. This frequently causes the superimposition of ideas and concepts and bingo! . . .out pops a new idea. This does not happen when you hunt for information via databases. However, invariably when I go directly to the printed journal or to the printed version of Chemical $A b$ stracts, I will very frequently uncover interesting and useful articles during the process of flipping pages to find the articles I was looking for in the first place.

A geologist agrees: "Nothing beats wandering around and 'discovering' literature in your own library, provided it is well stocked. I can't give a percentage, but it's amazing how often I just open up a book or a journal to a relevant reference."

Current Awareness Services. Current awareness services played a minor role in access, whether online/CD-ROM or in traditional paper format. A notable exception was Current Contents on Diskette with Abstracts, which received lavish praise from users. In some respects, this service with its abstracts and weekly updating can effectively substitute for can- celed subscriptions. Cost is high, however. With an individual subscription in 1993 ranging from $\$ 750$ (Agriculture, Biology \& Environmental Sciences; Physical, Chemical \& Earth Sciences; or Clinical Medicine) to $\$ 965$ (Life Sciences J-1200 Series) and the networked version considerably more, many scientists find it out-of-reach, financially.

Professional Meetings. Learning about references through contacts at conferences, seminars, etc., was especially important for mathematicians, third only to personal contacts and literature references. Several described the value of meeting other researchers at conferences, hearing their papers, and keeping up with their work henceforth. A botanist recalls, "I had met him earlier at a seminar. Since I knew him, when I started to do research in this area, I looked up his work." (This statement illustrates the difficulty of distinguishing between the access modes of "personal contact" and "seminar or conference," a dilemma which was left up to the scientist to resolve.)

Role of the Librarian. Clearly, academic librarians have a critical role in providing their clientele with appropriate journal collections and access to those collections. However, in the present study only one librarian was given credit for actually alerting a faculty member to a specific article of interest. A few scientists compared their present academic services with former special library environments, suggesting that in the latter more individualized attention was available from the staff. One geologist who had previously worked for an oil company recalled how the librarian supplied new journal information (including the tables of contents) every morning through the public folder which users could scan, note ones of interest, and request copies, all electronically.

Other. Participants commented on several unique access methods which they placed in the category of "other." For example, a molecular geneticist described this interesting system:

At Washington State University, computer programs for the analysis of 
TABLE 3

HOW SCIENTISTS RETRIEVE JOURNAL ARTICLES

\begin{tabular}{lccccc}
\hline & $\begin{array}{c}\text { Physics } \\
\%\end{array}$ & $\begin{array}{c}\text { Chemistry } \\
\%\end{array}$ & $\begin{array}{c}\text { Biology } \\
\%\end{array}$ & $\begin{array}{c}\text { Mathematics } \\
\%\end{array}$ & $\begin{array}{c}\text { Geology } \\
\%\end{array}$ \\
\hline Library subscription & 73 & 71 & 58 & 52 & 49 \\
$\begin{array}{l}\text { Reprint, preprint, photocopy } \\
\text { from colleague }\end{array}$ & 16 & 12 & 19 & 39 & 35 \\
$\begin{array}{l}\text { Personal journal } \\
\text { Interlibrary loan }\end{array}$ & 3 & 10 & 13 & 0 & 9 \\
Electronic copy & 3 & 4 & 6 & 0 & 4 \\
Librarian gave it to me & 0 & 0 & 0 & 0 & 0 \\
Don't remember & 0 & 0 & 0 & 0 & 0 \\
Other & 5 & 2 & 0 & 3 & 4 \\
\hline & 0 & 2 & 3 & 6 & 0 \\
\hline
\end{tabular}

DNA and protein sequences are maintained in a central VADMS (Visualization, Analysis and Design in the Molecular Sciences) laboratory. The login process for this system requests that any published work assisted by the programs be appropriately referenced and gives the applicable references for the different programs. This is how we learned about the Deveraux et al. reference.

\section{Retrieval}

This section addresses the second research question posed initially: "How do scientists actually obtain a copy of the desired article?" Two principal methods of retrieval dominate all the disciplines: library subscription; and reprint, preprint, or photocopy from colleagues. Although library subscriptions are critical for everyone, physicists and chemists are the chief users, while mathematicians and geologists lead in obtaining copies from colleagues. Chemists, biologists, and geologists depend on their personal journals more than do physicists and mathematicians. The percentages in table 3 indicate relative use.

The continuing degradation of physical retrieval in their local libraries was a major concern for 44 percent of those who offered additional comments. Journal subscription cuts, both in place and proposed, were paramount; several participants pointed out major titles important to their own work which were no longer available locally. Even if a subscription remained on campus, the canceled title in their own branch library was sorely missed: "Imagine a chemistry library that no longer subscribes to Biochemistry!" A zoologist laments that "Our library has a grossly incomplete selection of journals in my area of research, hardly any foreign journals."

Other comments addressed long delays in the bindery, the lack of space which necessitates storage of older backfiles in remote locations, loss of journals by theft or negligence, poor management resulting in slow reshelving, missing and mutilated journals, and general inaccessibility. An amusing comment from a biologist indicated a certain lack of appreciation for library classification systems: "I like journals kept in a separate section in alphabetical order. I try to avoid libraries in which journals are randomly dispersed among the books."

As journal subscriptions continue to be cut, inadequate document delivery, that is, slow and expensive interlibrary loan, increasingly becomes a critical concern. (No one commented on commercial document delivery services.) A statistician states simply that "[there is] an unacceptably long delay between the time when the need first arises and when I receive a photocopy." Several scientists described delays of two to three months, pointing out that most requests are no longer of interest after such a long time. Some resort to bypassing the library en- 
tirely (it's faster and cheaper) yet resent the encroachment upon their time. A botanist points out:

[My biggest problem] is being able to obtain the article easily and rapidly-there have been many times when I want to refer to an article but am not certain if it will be of use-in such cases interlibrary loan can be too slow and require too much time and effort to be worthwhile. Libraries should improve the speed and ease of use of interlibrary loan. In some cases it has been easier for me to call a colleague at another institution where I know the desired journal is available and request a photocopy than to go to our own interlibrary loan desk (which should specialize in such a process!).

Rapid retrieval of articles, preprints, and conference proceedings through FTP on the Internet was the ideal solution for these (mostly) academic scientists; files could then be viewed on the scientist's screen and printed on the local laser printer if desired.

What, we might ask, is new here? The answer is that these particular academic scientists believe-in an age of new services such as CD-ROM networks and expanded access through the local PAC - that library service is worsening. Fewer titles are available locally with insufficient retrieval structures put in place to make up for their absence. With increased use of remote storage and fewer current titles, opportunities for browsing have decreased. A geologist comments, "Older journals tend to be put in storage-but as a geologist, I need frequent access to these volumes. The need to request individual volumes eliminates the possibility of serious browsing."

The solution to these dilemmas, expressed by a large majority of scientists in all the disciplines, was the hope for fast, efficient retrieval of the full text of journal articles stored online. CD-ROM, mentioned only occasionally, was an alter- native option. Rapid retrieval of articles, preprints, and conference proceedings through FTP on the Internet was the ideal solution for these (mostly) academic scientists; files could then be viewed on the scientist's screen and printed on the local laser printer if desired. Physicists were especially enthusiastic, due partly to their very favorable experiences with such services as Ginsparg's (Los Alamos) preprint bulletin boards on the Internet, as described by Taubes. ${ }^{17}$

Scientific Journal Publishing-Effects on Retrieval. A number of respondents expressed dissatisfaction with the "system" of scientific journal publishing, laying blame on commercial publishers, the publish-or-perish syndrome which keeps inferior journals in business, and the repetitive publication of nearly identical articles by the same author. A geologist comments:

Scientists pad their résumés by publishing the same work in both major and obscure journals, then cite themselves incessantly to give the appearance of legitimacy. The rest of the community is then forced to dig up these obscure references which are not carried by most libraries, wasting both time and resources. Employers should emphasize quality over quantity.

Another geologist suggests that "Scientists are going to need to stop publishing in the high-priced commercial journals to force them to decrease prices." More than one respondent suggested canceling all journals published by certain European commercial publishers.

\section{CONCLUSIONS}

This study investigated the methods which scientists use for the access and retrieval of journal articles, providing contrasts among disciplines and uncovering some problems, preferences, and hopes for the future. Findings have implications for present and future roles played by the academic library in serving its scientific clientele.

The academic library would benefit from increased marketing and public relations, as scientists are frequently unaware of policies and services. Several 
comments from participants in this study illustrate this point. For example, a chemist stated, "An electronic version of the Science Citation Index would be the most valuable reference tool for journal article access that I can think of. Maybe someday it will be available to libraries and individuals." Unaware of publishers' mailing policies, a biologist assumed that his library delayed more than a week in shelving new journals since he received his personal copies much earlier than they appeared in the library. A university chemist explained that what he most needed was a way to find out when upcoming foreign conferences in his field were to be held. Such anecdotes suggest the need for a more proactive, aggressive stance toward marketing services and correcting users' misconceptions.

As cancellation continues, where does that leave scientists who depend heavily on direct access to the published literature through local collections?

Library literature is replete with predictions that university libraries will continue to undergo transformation from warehouses for stored, printed materials into gateways for electronic access to information. Thus, as access is separated from ownership, questions of physical location will become secondary. In the meantime, slower growth in library acquisition budgets means less access to scholarly resources within the library.

The ARL report points out that "pressure on acquisitions budgets will cause various research libraries to look more and more alike over time, as each ceases to purchase as many of the more esoteric publications and chooses rather to be sure that essential volumes are acquired."18 Some of the scientists in this study would argue that their institutions have begun canceling journals which are critical to their fields and are certainly far from "esoteric." As cancellation continues, where does that leave scientists who depend heavily on direct access to the published literature through local collections? After all, depending on the discipline, 49 to 73 percent of the physical retrieval of articles in this study was through library subscriptions.

While some academic librarians propose that scientists will use the library as an electronic gateway, others like S. M. Malinconico warn that the future may not be so straightforward. Various agencies, on and off campus, have a stake in information resources and are perfectly capable of providing sophisticated electronic access. ${ }^{19}$ As more full-text electronic resources become available, scientists will access them directly. Academic physicists already lead the way in bypassing libraries through their rapidly expanding use of preprint bulletin boards in subdisciplines such as highenergy particle theory, astrophysics, general relativity, and nuclear theory. As increasing numbers of scientific journal publishers like Elsevier and the American Society for Microbiology offer electronic access and retrieval, problems of who will pay, peer review, integrity of the electronic record, and archiving must be addressed.

What, then, is the emerging role of the academic library as far as its scientific clientele is concerned? In addressing this question, information professionals should give serious consideration to differences in access and retrieval among disciplines, some of which are suggested in this study. Related questions also come to mind. How should electronic availability (perhaps quite expensive) affect collection development? Should academic libraries opt for increased efforts in cooperative acquisitions so that they don't look "more and more alike"? What are the long-term implications for users who find electronic access prohibitively expensive?

Regardless of present and future electronic innovations, findings of this study suggest that scientists feel increasingly cut off and remote from their journal literature that is becoming more and more inaccessible. Most academic scientists have very simple expectations for 
the library. They do not demand electronic services which are (or will be) available from their own desktops. They do expect and need fast, efficient, and inexpensive document delivery for material not owned and not available electronically. If the library is cutting thousands of dollars of journal subscriptions, scientists point out, surely more emphasis should be placed on document delivery. Thus, scientists who participated in this study would urge their librarian colleagues, when defining new roles and services for the "library without walls," to place the highest priority on fast, efficient retrieval of journal articles, still the primary vehicle for scientific communication.

\section{REFERENCES AND NOTES}

1. James L. Smith, "Faxon Client Communication Update," (Sept. 9, 1992).

2. Adrian Alexander, "Periodical Prices, 1990-1992," Library Acquisitions: Practice and Theory 17 (Spring 1993): 3-20.

3. University Libraries and Scholarly Communication: A Study Prepared for the Andrew W. Mellon Foundation. (n.p.: Association of Research Libraries, 1992).

4. H. H. Barschall, "The Cost-Effectiveness of Physics Journals," Physics Today 41 (July 1988): 56-59.

5. H. H. Barschall and J. R. Arrington, "Cost of Physics Journals: A Survey," Bulletin of the American Physical Society 33 (1988): 1437-47.

6. Nancy Pruett, Scientific and Technical Libraries, 2 vols. (San Diego, Calif.: Academic, 1986).

7. Panel on Information Technology and the Conduct of Research, Information Technology and the Conduct of Research: The User's View (Washington, D.C.: National Academy Pr., 1989).

8. Constance C. Gould and Karla Pearce, Information Needs in the Sciences: An Assessment (Mountain View, Calif.: Research Libraries Group, 1991).

9. D. W. King, and others, Statistical Indicators of Scientific and Technical Communication, vol. 1 of A Summary Report (Washington, D.C.: National Science Foundation, 1977). Contract C-DSI-75-06942. Rockville, Md.: King Research, Inc., 1977.

10. Bill Katz and Linda S. Katz, Magazines for Libraries, 6th ed. (New York: Bowker, 1989).

11. King, Statistical Indicators of Scientific and Technical Communication (1960-1980), vol. 1 of A Summary Report.

12. Ibid.

13. Julie Bichteler and Dederick Ward, "Information Seeking Behavior of Geoscientists," Special Libraries 80 (Summer 1989): 169-78.

14. A. Gralewska-Vickery, "Communication and Information Needs of Earth Science Engineers," Information Processing and Management 12, no. 4 (1976): 251-82.

15. Damon Ridley, conversation with author, University of Sydney, June 10, 1992.

16. King, Statistical Indicators of Scientific and Technical Communication (1960-1980), vol. 1 of A Summary Report.

17. Gary Taubes, "Publication by Electronic Mail Takes Physics by Storm," Science 259 (1993): $1246-48$.

18. University Libraries and Scholarly Communication: A Study Prepared for the Andrew W. Mellon Foundation.

19. S. Michael Malinconico, "What Librarians Need to Know to Survive in an Age of Technology," Journal of Education for Library and Information Science 33, no. 3 (1992): 226-40. 


\section{APPENDIX A}

March 23, 1992

Dr. John Doe

Geological Research Division

Scripps Institution of Oceanography

La Jolla, California 92093-0215

Dear Dr. Doe:

In your recent article, "Ocean nutrient distribution and oxygenation: Limits on the formation of warm saline bottom water over the past 91 m.y.," published last year in Geology, you cited the following reference:

Wright, J.D., Miller, K.G., and Fairbanks, R.G., 1991. Evolution of modern deep-water circulation: Evidence from the late Miocene southern ocean: Paleoceanography (in press)

I am investigating the ways by which scientists in various disciplines first become aware of and then actually obtain the journal articles which they cite. The journal crisis in this country seems to be continuing unabated, with significant increases in subscription rates announced for 1992 along with further massive cancellations by libraries. Studies such as this one which contribute to our knowledge of the information-seeking behavior of scientists should provide useful data for improving access to the journal literature, so critical to the scientific endeavor.

Would you please take a moment to complete the enclosed brief form and return it to me in the self-addressed envelope? If a co-author came up with this reference, please forward this request to that person.

Thanks very much for your help.

Sincerely,

Julie Hallmark

Professor

Graduate School of Library and Information Science

The University of Texas at Austin

Enc. 


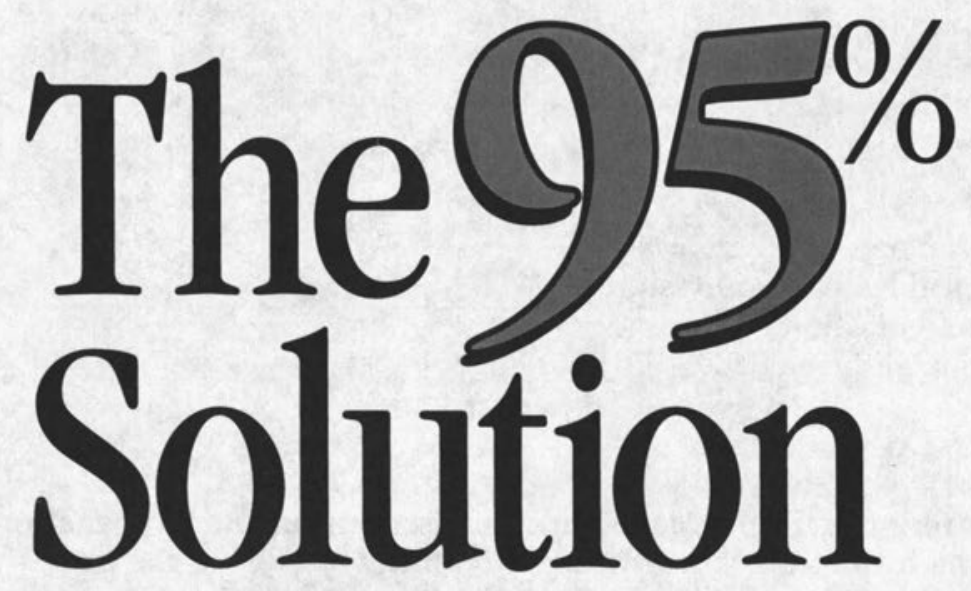

You get one chance with authority control, so it's important to get it done right. LTI guarantees that its affordable, machine-only authority control will link $95 \%$ or more of your library's controlled headings to an LC or LTI authority record. No exceptions! No excuses!

When manual review is requested, only professional librarians are used as editors and link rates approach $100 \%$.

LTI maintains the complete LC MARC authority files (updated weekly), supplemented with over 410,000 LTI authority records and 350,000 proprietary "cross links."

Contact LTI for more information on authority record link results.

"Authority Control for the 21st Century"

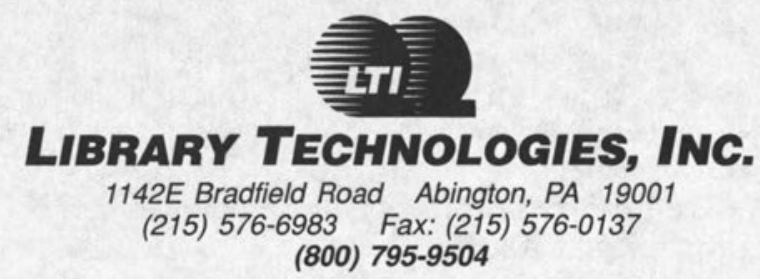

